\title{
Elevated Admission Base Deficit Is Associated with a Complex Dynamic Network of Systemic Inflammation Which Drives Clinical Trajectories in Blunt Trauma Patients
}

\author{
Othman Abdul-Malak, ${ }^{1}$ Yoram Vodovotz, ${ }^{1,2}$ Akram Zaaqoq, ${ }^{3}$ Jesse Guardado, \\ Khalid Almahmoud, ${ }^{1}$ Jinling Yin, ${ }^{1}$ Brian Zuckerbraun, ${ }^{1}$ Andrew B. Peitzman, ${ }^{1}$ \\ Jason Sperry, ${ }^{1}$ Timothy R. Billiar, ${ }^{1,2}$ and Rami A. Namas ${ }^{1,2}$ \\ ${ }^{1}$ Department of Surgery, University of Pittsburgh, Pittsburgh, PA 15213, USA \\ ${ }^{2}$ Center for Inflammation and Regenerative Modeling, McGowan Institute for Regenerative Medicine, \\ University of Pittsburgh, Pittsburgh, PA 15219, USA \\ ${ }^{3}$ Department of Critical Care Medicine, University of Pittsburgh, PA 15213, USA
}

Correspondence should be addressed to Rami A. Namas; namasra2@upmc.edu

Received 16 August 2016; Accepted 10 October 2016

Academic Editor: Vera L. Petricevich

Copyright (C) 2016 Othman Abdul-Malak et al. This is an open access article distributed under the Creative Commons Attribution License, which permits unrestricted use, distribution, and reproduction in any medium, provided the original work is properly cited.

\begin{abstract}
We hypothesized that elevated base deficit $(\mathrm{BD}) \geq 4 \mathrm{mEq} / \mathrm{L}$ upon admission could be associated with an altered inflammatory response, which in turn may impact differential clinical trajectories. Using clinical and biobank data from 472 blunt trauma survivors, 154 patients were identified after excluding patients who received prehospital IV fluids or had alcohol intoxication. From this subcohort, 84 patients had a $\mathrm{BD} \geq 4 \mathrm{mEq} / \mathrm{L}$ and 70 patients with $\mathrm{BD}<4 \mathrm{mEq} / \mathrm{L}$. Three samples within the first $24 \mathrm{~h}$ were obtained from all patients and then daily up to day 7 after injury. Twenty-two cytokines and chemokines were assayed using Luminex $^{\mathrm{TM}}$ and were analyzed using two-way ANOVA and dynamic network analysis (DyNA). Multiple mediators of the innate and lymphoid immune responses in the $\mathrm{BD} \geq 4$ group were elevated differentially upon admission and up to $16 \mathrm{~h}$ after injury. DyNA revealed a higher, sustained degree of interconnectivity of the inflammatory response in the $\mathrm{BD} \geq 4$ patients during the initial $16 \mathrm{~h}$ after injury. These results suggest that elevated admission BD is associated with differential immune/inflammatory pathways, which subsequently could predispose patients to follow a complicated clinical course.
\end{abstract}

\section{Introduction}

Traumatic injury can result in sudden metabolic and physiological alterations that are frequently proportionate to the degree and magnitude of the injury sustained [1-3]. Consequently, the host's homeostatic mechanisms-often driven or accompanied by a broad systemic inflammatory response-attempt to correct for these metabolic perturbations and restore normal body functions $[4,5]$. However, with significant disruption of the homeostatic mechanism and inability to compensate for these metabolic changes, cellular hypoperfusion and metabolic acidosis ensue $[6,7]$. Further complicating the clinical scenario is the extent of the perpetuated metabolic derangement that could propagate the trauma-induced inflammatory response $[4,8-10]$. This results in a positive self-feedback loop of inflammation driving damage or dysfunction, which in turn stimulates further inflammation [11-13]. We and others have hypothesized that the outcome of this vicious cycle eventually leads to immune dysregulation, which predispose trauma patients to develop complications such as multiple organ failure and nosocomial infections [14-17].

The early identification and correction of significant metabolic disturbances are one of the key components in managing critically ill patients [6, 18-20]. Blood lactate and arterial base deficit (BD) are the most commonly used circulating markers of systemic metabolic acidosis [2, 21-24]. Multiple studies have validated the usefulness of blood lactate 
and $\mathrm{BD}$ in trauma patients as markers of injury severity [25$28]$, as endpoints of resuscitation $[20,29]$, as a means to monitor treatment efficacy [30-32], and as predictors of outcome [33-36]. Despite indicating the severity of hypoperfusion [37, 38], measurement of lactate alone may not fully encompass the extent of the underlying metabolic acidosis [39]. On the contrary, BD can quantify the extent of both anaerobic and aerobic acidosis and may be a better clinical indicator for the global assessment of the metabolic acid-base status [32, 3941]. In addition, prior studies have suggested that elevated arterial $\mathrm{BD}(\geq 4 \mathrm{mEq} / \mathrm{L})$ upon admission after injury can be a reliable predictor of multiple organ dysfunction, morbidity, and mortality in moderately/severely injured patients $[21,34$, 36, 42-44].

Despite the large volume of published data studying the utility of arterial $\mathrm{BD}$ among trauma patients, no study to date has examined the temporal effect of metabolic derangement, suggested by elevated $\mathrm{BD}$, on the dynamics of the trauma-induced inflammation. In addition, it is not clear which immune phenotypes are associated with the ensuing metabolic disturbance in trauma patients who follow a complicated clinical course. To address this complexity, we analyzed clinical and inflammatory biomarker data from a cohort of 472 blunt trauma survivors. To reduce the possible impact of confounding variables, we excluded patients who received large volumes ( $>2$ liters) of intravenous fluids or blood components en route, as well as patients with alcohol intoxication upon admission. After applying these exclusion criteria, we sought to derive two subgroups based on a BD cutoff of below and above $4 \mathrm{mEq} / \mathrm{L}$.

These selection criteria yielded two subgroups of patients with admission $\mathrm{BD}<4$ versus $\mathrm{BD} \geq 4$. Plasma samples from these two groups were analyzed subsequently for dynamic changes in inflammatory mediators. Our results revealed that patients in the $\mathrm{BD} \geq 4$ group exhibited an early, differential immune profile upon admission independent of age, gender, and injury severity. In parallel to these results, data-driven modeling suggested a higher, sustained degree of activation of both innate and lymphoid pathways in the $\mathrm{BD} \geq 4$ group when compared to $\mathrm{BD}<4$ group. Collectively, these analyses suggest that $\mathrm{BD} \geq 4 \mathrm{mEq} / \mathrm{L}$ after injury could drive differential immune pathways, which in turn may predispose trauma patients to develop adverse in-hospital outcomes.

\section{Methods}

2.1. Patient Enrollment and Sampling. All human sampling was carried out following approval by the University of Pittsburgh Institutional Review Board (IRB), and informed consent was obtained either from the patient or from the next of kin, as per IRB regulations. Patients who deemed eligible for enrollment were at least 18 years of age at time of the trauma, admitted to the Intensive Care Unit (ICU) as part of the posttrauma management, and were expected to survive beyond the initial $24 \mathrm{~h}$ after injury as per the on-call trauma surgeon. Reasons for ineligibility were isolated head injury or brain death criteria, pregnancy, and penetrating trauma. Three plasma samples, starting with the initial blood draw upon arrival, were assayed within the first $24 \mathrm{~h}$ following injury and then from days 1 to 7 after injury. The blood samples were centrifuged, and plasma aliquots were stored in cryopreservation tubes at $-80^{\circ} \mathrm{C}$ for subsequent analysis of inflammatory mediators.

2.2. Data Collection. Demographic and clinical data including ICU length of stay (LOS), hospital LOS, days on mechanical ventilation, arterial $\mathrm{BD}$, lactic acid, heart rate, systolic blood pressure, injury severity score (ISS) [45], the abbreviated injury scale (AIS) [46], Glasgow coma scale (GCS), the Marshall Multiple Organ Dysfunction Score (MODScore) [47] (which was calculated daily as described previously [17]), and the Shock Index [48] (which identifies the degree of shock in trauma patients, calculated based upon the ratio of heart rate to the systolic blood pressure, where an index $>1$ signifies hypovolemic shock) were collected from the inpatient electronic medical record and the trauma registry database.

2.3. Study Design and Selection of Subgroups. Using a prospectively maintained clinical database and biobank of 472 blunt trauma survivors (after excluding 21 nonsurvivors) admitted or transferred to Emergency Department (ED) of the Presbyterian University Hospital (Level 1 trauma center), the salient characteristics of which were described recently [17]. Initially, we sought to reduce possible confounding factors that might affect admission BD. Prior studies have suggested that increased serum ethanol levels could alter $\mathrm{BD}$ values independent of other factors such as initial blood pressure, injury severity, and the amount of blood loss [49-51]. Accordingly, patients with documented alcohol intoxication (defined as serum ethanol level > $10 \mathrm{ng} / \mathrm{dL}$ ) upon admission to the ED were excluded from the analysis. Another possible confounder for which we sought to control was the administration of crystalloids and blood products prior to ED admission. While crystalloids and blood products are an integral component for the management of patients in shock, administration of large volumes of crystalloids and blood components can significantly alter BD values [52-55]. Accordingly, patients who received large volumes of fluids or blood products ( $>2$ liters) en route were further excluded from the analysis.

After applying these aforementioned inclusion and exclusion criteria (see above), we next sought to derive two subgroups of trauma patients based on admission BD values. Prior studies have suggested that an initial arterial $\mathrm{BD}$ value of $>4 \mathrm{mEq} / \mathrm{L}$ was associated with increased patient mortality and development of organ failure [21, 43, 44]. Thus, we applied a BD cutoff value of $4 \mathrm{mEq} / \mathrm{L}$, which segregated trauma patients into two distinct groups: $\mathrm{BD}<4(n=70)$ and $\mathrm{BD} \geq 4(n=84)$. The subgroups were then subsequently analyzed for differences in clinical outcome, development of organ dysfunction, disposition, inflammatory biomarker trajectories, and dynamic inflammatory network connectivity.

2.4. Inflammation Biomarker Analysis. Blood samples were collected into citrated tubes via peripheral venous, central venous, or arterial catheterization within $24 \mathrm{~h}$ of admission and daily up to 7 days after injury. The blood samples 
were centrifuged, and plasma was stored in multiple aliquots at $-80^{\circ} \mathrm{C}$ for subsequent analysis of inflammatory mediators. The human inflammatory MILLIPLEX ${ }^{\mathrm{TM}}$ MAP Human Cytokine/Chemokine Panel-Premixed 24 Plex, MILLIPLEX MAP Human Th17 Panel (Millipore Corporation, Billerica, MA), and Luminex 100 IS analyzer (Luminex, Austin, TX) were used to measure plasma levels of interleukin $1 \beta$ (IL- $1 \beta$ ), IL-1 receptor antagonist (IL-1RA), IL-2, soluble IL-2 receptor$\alpha$ (sIL-2R $\alpha$ ), IL-4, IL-5, IL-6, IL-7, IL-8 (CCL8), IL-10, IL-13, IL-15, IL-17A, interferon $\gamma($ IFN- $\gamma)$, IFN- $\gamma$ inducible protein 10 (IP-10) (CXCL10), monokine induced by gamma interferon (MIG; CXCL9), macrophage inflammatory protein $1 \alpha$ $(\mathrm{MIP}-1 \alpha)$ (CCL3), MIP-1 $\beta$ (CCL4), monocyte chemotactic protein 1 (MCP-1) (CCL2), granulocyte-macrophage colony stimulating factor (GM-CSF), Eotaxin (CCL11), and tumor necrosis factor alpha (TNF- $\alpha$ ). The Luminex system was used in accordance to the manufacturer's instructions.

2.5. Statistical Analysis. All data were analyzed using SigmaPlot ${ }^{\mathrm{TM}} 11$ software (Systat Software, Inc., San Jose, CA) and GraphPad PRISM (GraphPad Software, Inc., La Jolla, CA). Statistical difference between subgroups was determined by either Mann-Whitney $U$ test, Chi-square, or Hazard Ratio as appropriate. Group-time interaction of plasma inflammatory mediators' levels was determined by two-way analysis of variance (ANOVA). To quantify the overall production of the statistically significant mediators, we calculated the area under the curve (AUC) using the mean values for each time point in a given time frame and then calculated the fold change difference between the two subgroups. $P<0.05$ was considered statistically significant for all analyses.

2.6. Data-Driven Modeling: Dynamic Network Analysis $(D y N A)$. The goal of this analysis was to gain insights into the temporal dynamic changes in network interconnectivity and complexity of the posttraumatic inflammatory response between the $\mathrm{BD}<4$ and $\mathrm{BD} \geq 4$ subgroups. The mathematical formulation of this method is to calculate the correlation among inflammatory mediators by which we can examine their dependence across time. To do so, inflammatory mediator networks were created in adjacent $8 \mathrm{~h}$ time periods over the first $24 \mathrm{~h}(0-8 \mathrm{~h}, 8-16 \mathrm{~h}$, and $16-24 \mathrm{~h})$ using MATLAB $^{\circledR}$ (The MathWorks, Inc., Natick, MA) as we have done previously $[17,56,57]$. Connections in the network were created if the correlation coefficient between two nodes (inflammatory mediators) was greater or equal to a threshold of 0.7 . For the network density calculation, in order to account for network sizes (number of significantly altered nodes) in the adjacent 8-h time periods detailed above, we utilized the following formula:

Network Density

$$
=\frac{\text { Total number of egdes } \times \text { Number of total nodes }}{\text { Maximum possible edges among total nodes }} \text {. }
$$

\section{Results}

3.1. Demographics and Clinical Outcomes of Study Subgroups. The overall study cohort consisted of 472 blunt trauma survivors who were admitted to the ICU after being resuscitated, which was described recently [17]. Of these patients and based on selection criteria (see Section 2), we identified 70 patients with an admission $\mathrm{BD}<4 \mathrm{mEq} / \mathrm{L}$ (age: $49 \pm 2$; male/female [M/F]: 55/15; ISS: $21 \pm 1$; and GCS: $13 \pm 0.5)$ and 84 patients with an admission $\mathrm{BD} \geq 4 \mathrm{mEq} / \mathrm{L}$ (age: $46 \pm 2$; M/F: 55/29; ISS: $23 \pm 1$; and GCS: $13 \pm 0.6)$. Overall, males were predominant in both $\mathrm{BD}<4$ and $\mathrm{BD} \geq 4$ groups $(78.6 \%$ and $65.5 \%$ resp.; $P=0.07)$ with no statistical difference in mean age $(P=0.3)$ between the two subgroups. In addition, both $\mathrm{BD}<4$ and $\mathrm{BD} \geq 4$ groups sustained trauma in different forms, with motor vehicle crashes being the predominant mechanism of injury (67\% and 65\%, resp.). There was no statistical difference in the mechanism of injury $(P=0.9)$ and ISS $(P=0.1)$ between the two subgroups. Importantly, the ICU LOS $(P=0.005)$, hospital LOS $(P<0.001)$, and days on mechanical ventilation $(P=0.02)$ were all statistically significantly longer in the $\mathrm{BD} \geq 4$ group when compared to the $\mathrm{BD}<4$ group (see Table 1 ).

3.2. Biochemical and Physiological Parameters. Since our study subgroups were selected based on admission BD values, we next sought to examine time course changes in $\mathrm{BD}$ across multiple time points within the first $24 \mathrm{~h}$ and up to day 7 after injury. As expected per our study design, the admission BD was statistically significantly elevated at $8 \mathrm{~h}$ after injury in the $\mathrm{BD} \geq 4$ group when compared to the $\mathrm{BD}<4$ group $(6.7 \pm 0.4$ versus $1.7 \pm 0.1$ resp.; $P<0.001$; Figure $1(\mathrm{a}))$. Although these elevations persisted up to $16 \mathrm{~h}$ after injury, $\mathrm{BD}$ values in the $\mathrm{BD} \geq 4$ group declined significantly at $24 \mathrm{~h}$, reaching levels similar to those of the $\mathrm{BD}<4$ group from days 1 to 7 after injury (Figure 1(a)). Given that BD is a surrogate marker of lactic acid accumulation and hence metabolic acidosis [53], we next sought to determine venous lactate levels at the corresponding time points in which $\mathrm{BD}$ values were assessed. This analysis revealed that the $\mathrm{BD} \geq 4$ group had statistically significantly higher lactate levels upon admission when compared to the $\mathrm{BD}<4$ group $(3.4 \pm 0.3$ versus $2.1 \pm 0.1$ resp.; $P<0.001$; Figure $1(\mathrm{~b}))$. Thereafter, lactate levels declined steadily within $24 \mathrm{~h}$ of injury reaching normal ranges by day 2 and up to day 7 after injury (Figure 1(b)).

Vital signs are an integral part of the initial cache of parameters used to assess the degree of shock. Current standards of care resuscitation guidelines following trauma or hemorrhagic shock are almost exclusively based on parameters such as the systolic blood pressure (SBP), heart rate (HR), and the mean arterial pressure (MAP) [58-60]. Analysis of these physiological parameters showed that the $\mathrm{BD} \geq 4$ group had a statistically significantly lower mean admission SBP when compared to the $\mathrm{BD}<4$ group $(114 \pm 3 \mathrm{mmHg}$ versus $130 \pm 3$ mmHg resp.; $P<0.001$; Figure $2(a))$. In addition, the $\mathrm{BD} \geq 4$ group had a statistically significantly higher mean $\mathrm{HR}$ when compared to the $\mathrm{BD}<4$ group $(104 \pm 3 \mathrm{bpm}$ versus 89 \pm 2 bpm resp.; $P<0.001$; Figure 2(b)). However, there was no statistically significant difference $(P=0.78)$ with regard to the proportion of patients with overt hypotension (defined as $\mathrm{MAP}<60 \mathrm{mmHg}$ ) upon admission in the $\mathrm{BD} \geq 4$ group $(5 / 84[6 \%])$ when compared to the $\mathrm{BD}<4$ group $(2 / 70[3 \%])$.

Next, we sought to evaluate the degree of shock between the two subgroups by calculating the Shock Index (SI; see 
TABLE 1: Overall demographics, clinical outcomes, mechanism of injury, blood and blood components, comorbidities, and disposition of the $\mathrm{BD}<4(n=70)$ and $\mathrm{BD} \geq 4(n=84)$ subgroups. Values are expressed as mean \pm SEM. Mann-Whitney $U$ test, Fisher exact test, or Chi-square were used as appropriate with statistical significance set at $P<0.05$.

\begin{tabular}{|c|c|c|c|}
\hline & $\begin{array}{l}\mathrm{BD}<4 \\
n=70\end{array}$ & $\begin{array}{c}\mathrm{BD} \geq 4 \\
n=84\end{array}$ & $P$ value \\
\hline \multicolumn{4}{|l|}{ Demographics } \\
\hline Age, yr & $49.3 \pm 2.4$ & $45.76 \pm 2$ & 0.34 \\
\hline Sex, male/female & $\mathrm{M}=55 \mathrm{~F}=15$ & $\mathrm{M}=55 \mathrm{~F}=29$ & 0.07 \\
\hline Injury severity score (ISS) & $21 \pm 1.3$ & $23 \pm 1.2$ & 0.15 \\
\hline Glasgow coma scale (GCS) & $12.7 \pm 0.52$ & $12.6 \pm 0.56$ & 0.46 \\
\hline \multicolumn{4}{|l|}{ Outcome } \\
\hline Intensive Care Unit length of stay, days & $6.6 \pm 0.79$ & $9.9 \pm 0.96$ & 0.005 \\
\hline Hospital length of stay, days & $11.9 \pm 0.97$ & $17.4 \pm 1.2$ & $<0.001$ \\
\hline Mechanical ventilation, days & $3 \pm 0.56$ & $5.5 \pm 0.87$ & 0.02 \\
\hline \multicolumn{4}{|l|}{ Mechanism of Injury } \\
\hline Motor vehicle crashes (MVC), $n(\%)$ & $47(67 \%)$ & $55(65 \%)$ & 0.98 \\
\hline Fall, $n(\%)$ & $8(11.5 \%)$ & $10(12 \%)$ & \\
\hline Motorcycle, $n(\%)$ & $8(11.5 \%)$ & $9(11 \%)$ & \\
\hline Others, $n(\%)$ & $7(10 \%)$ & $10(12 \%)$ & \\
\hline \multicolumn{4}{|l|}{ Blood and Blood Components } \\
\hline 24 h packed RBC, $n(\%)$ & $10(14.3 \%)$ & $27(32.2 \%)$ & 0.001 \\
\hline $24 \mathrm{~h}$ blood components (platelets, FFP, and cryoprecipitate), $n(\%)$ & $4(5.7 \%)$ & $0(0 \%)$ & \\
\hline $24 \mathrm{~h}$ PRBC + other components (platelets, FFP, and cryoprecipitate), $n(\%)$ & $6(8.6 \%)$ & $16(19 \%)$ & \\
\hline None, $n(\%)$ & $50(71.4 \%)$ & $41(48.8 \%)$ & \\
\hline \multicolumn{4}{|l|}{ Comorbid Conditions } \\
\hline Hypertension, $n(\%)$ & $22(31.4 \%)$ & $20(23.8 \%)$ & 0.3 \\
\hline Diabetes mellitus, $n(\%)$ & $10(14.3 \%)$ & $9(10.7 \%)$ & 0.5 \\
\hline Smoking, $n(\%)$ & $4(5.7 \%)$ & $6(7.2 \%)$ & 0.7 \\
\hline Cardiovascular, $n(\%)$ & $10(14.3 \%)$ & $12(14.3 \%)$ & 1 \\
\hline Pulmonary, $n(\%)$ & $3(4.3 \%)$ & $8(9.5 \%)$ & 0.2 \\
\hline Endocrine, $n(\%)$ & $15(21.4 \%)$ & $8(9.5 \%)$ & 0.04 \\
\hline Gastrointestinal, $n(\%)$ & $6(8.6 \%)$ & $5(6 \%)$ & 0.5 \\
\hline Peripheral vascular disease, $n(\%)$ & $2(2.9 \%)$ & $0(0 \%)$ & 0.12 \\
\hline Neurological, $n(\%)$ & $8(11.4 \%)$ & $4(4.8 \%)$ & 0.12 \\
\hline Psychiatric, $n(\%)$ & $6(8.6 \%)$ & $9(10.7 \%)$ & 0.65 \\
\hline Drug and Alcohol Abuse, $n(\%)$ & $4(5.7 \%)$ & $4(4.8 \%)$ & 0.79 \\
\hline Renal, $n(\%)$ & $0(0 \%)$ & $4(4.8 \%)$ & 0.06 \\
\hline Rheumatologic, $n(\%)$ & $0(0 \%)$ & $4(4.8 \%)$ & 0.06 \\
\hline Hematologic, $n(\%)$ & $3(4.3 \%)$ & $1(1.2 \%)$ & 0.23 \\
\hline Previous admission for trauma, $n(\%)$ & 0 & $1(1.2 \%)$ & 0.36 \\
\hline None, $n(\%)$ & $22(31.4 \%)$ & $32(38.1 \%)$ & 0.39 \\
\hline \multicolumn{4}{|l|}{ Disposition } \\
\hline Home, $n(\%)$ & $34(48.6 \%)$ & $23(27.4 \%)$ & 0.005 \\
\hline Home with service, $n(\%)$ & $2(2.9 \%)$ & $1(1.2 \%)$ & \\
\hline Inpatient rehabilitation facility, $n(\%)$ & $6(8.6 \%)$ & $1(1.2 \%)$ & \\
\hline Outpatient rehabilitation facility, $n(\%)$ & $11(15.7 \%)$ & $17(20.2 \%)$ & \\
\hline Skilled nursing facility, $n(\%)$ & $16(22.9 \%)$ & $39(46.4 \%)$ & \\
\hline Others, $n(\%)$ & $1(1.4 \%)$ & $3(3.6 \%)$ & \\
\hline
\end{tabular}




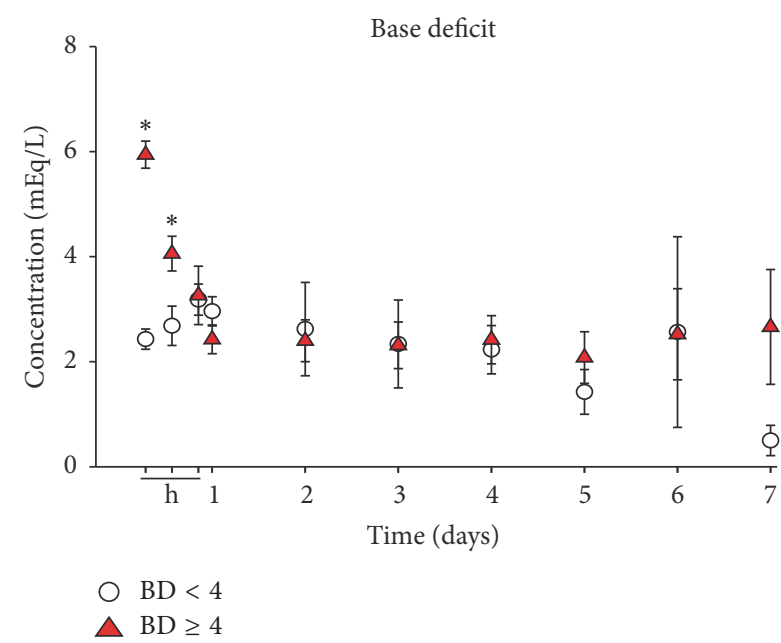

(a)



(b)

Figure 1: (a) Arterial base deficit (BD) from time of admission up to 7 days after injury between $\mathrm{BD} \geq 4$ and $\mathrm{BD}<4$ subgroups. The BD $\geq 4$ group had statistically significantly elevated BD levels at $8 \mathrm{~h}$ and $16 \mathrm{~h}$ after injury when compared to the $\mathrm{BD}<4$ group. BD in both subgroups approach similar values at $24 \mathrm{~h}$ after injury. ${ }^{*} \mathrm{P}<0.05$ by two-way ANOVA. (b) Plasma lactate levels from time of admission up to 7 days after injury between $\mathrm{BD} \geq 4$ and $\mathrm{BD}<4$ subgroups. The $\mathrm{BD} \geq 4$ group had statistically significantly elevated lactate levels at $8 \mathrm{~h}$ after injury when compared to the $\mathrm{BD}<4$ group. $\mathrm{BD}$ in both subgroups approaches normal values at $24 \mathrm{~h}$ after injury. ${ }^{*} \mathrm{P}<0.05$ by two-way ANOVA.

Section 2). The $\mathrm{BD} \geq 4$ group had statistically significantly higher degree of shock when compared to $\mathrm{BD}<4$ group (SI: $0.96 \pm 0.03$ versus $0.7 \pm 0.02$, resp.; $P<0.001$; Figure 2 (c)). We suggest that these physiological differences between the two subgroups could reflect the hypoperfusion status occurring at the tissue level in otherwise apparently stable trauma patients.

\subsection{Body Region Involvement and Development of Multiple} Organ Dysfunction. Although the ISS was not statistically significantly different between the two subgroups, an analysis of the AIS revealed a statistically significantly $(P<0.05)$ higher degree of extremity injury in the $\mathrm{BD} \geq 4$ group when compared to $\mathrm{BD}<4$ group (Figure $3(\mathrm{a})$ ). In addition, the $\mathrm{BD}$ $<4$ and $\mathrm{BD} \geq 4$ subgroups differed in their degree of multiple organ dysfunction (MOD), as indicated by the Marshall MODScore [47], which was calculated at each relevant time point in which inflammation biomarkers were assessed. This analysis suggested that the $\mathrm{BD} \geq 4$ group had a persistently elevated mean MODScore from day 1 through day 7 after injury, being statistically significantly higher $(P<0.001)$ at day 2 through day 4 when compared to $\mathrm{BD}<4$ group (Figure 3(b)).

3.4. Inpatient Management and Hospital Discharge. Blood and blood components are integral part of management in trauma patients who present with clinically observable hypotension $(\mathrm{SBP}<90 \mathrm{mmHg}$ ) or hypovolemic shock refractory to crystalloid resuscitation. Analysis of blood transfusion requirement revealed that $43 / 84$ patients $(51 \%)$ of the $\mathrm{BD} \geq 4$ group required blood transfusion in the first $24 \mathrm{~h}$ after injury as compared to $22 / 70$ patients $(31 \%)$ in the $\mathrm{BD}<4$ group (Table 1). This analysis suggested that hypotensive patients with admission $\mathrm{BD} \geq 4 \mathrm{mEq} / \mathrm{L}$ had a 1.7 -fold risk for requiring blood transfusion $(P=0.012)$ within the initial $24 \mathrm{~h}$ after injury.
The decision to perform urgent surgical interventions after trauma is based on a combination of clinical parameters and diagnostic tests that are performed in the ED/trauma bay $[60,61]$. We hypothesized that standard measurement of admission BD could improve the existing standards of care and aid clinicians during their initial assessment of patients who might require operative management. Accordingly, we identified $51 / 84$ patients $(61 \%)$ in the $\mathrm{BD} \geq 4$ group who required surgical interventions within the first $24 \mathrm{~h}$ after injury versus $29 / 70$ patients $(41 \%)$ in the $\mathrm{BD}<4$ group $(P=0.02$; Figure 4(a)). Next, we sought to calculate the relative risk (RR) of requiring surgical intervention in patients presenting to the $\mathrm{ED}$ with $\mathrm{BD}>4 \mathrm{mEq} / \mathrm{L}$. This analysis revealed that patients in the $\mathrm{BD} \geq 4$ group have a higher $\mathrm{RR}$ of requiring operative management $(\mathrm{RR}=1.5,95 \%$ CI [1.056-2.033]; $P<0.05)$ when compared to patients in the $\mathrm{BD}<4$ group (Figure 4 (b)).

Several factors can affect the final disposition of trauma patients, in particular, early prehospital events such as severity of injury sustained and extent of tissue damage/loss after injury $[62,63]$. Subsequently, these factors can contribute significantly to the magnitude of the ensuing metabolic stress, which in turn is reflected by high BD values after trauma. Accordingly, we hypothesized that patients admitted to the ED with elevated admission BD could have a differential disposition upon hospital discharge. Our analysis of patients' disposition in both subgroups revealed that the $\mathrm{BD} \geq 4$ group had greater requirement $(P=0.005)$ for outpatient special care services $(72 \%)$ when compared to the $\mathrm{BD}<4$ group $(51 \%)$ (Table 1).

3.5. $B D \geq 4$ Group Exhibited a Differential Dynamic Systemic Inflammatory Profile. We next sought to examine the temporal dynamic patterns of circulating inflammation biomarkers between the $\mathrm{BD}<4$ and $\mathrm{BD} \geq 4$ subgroups from time of 


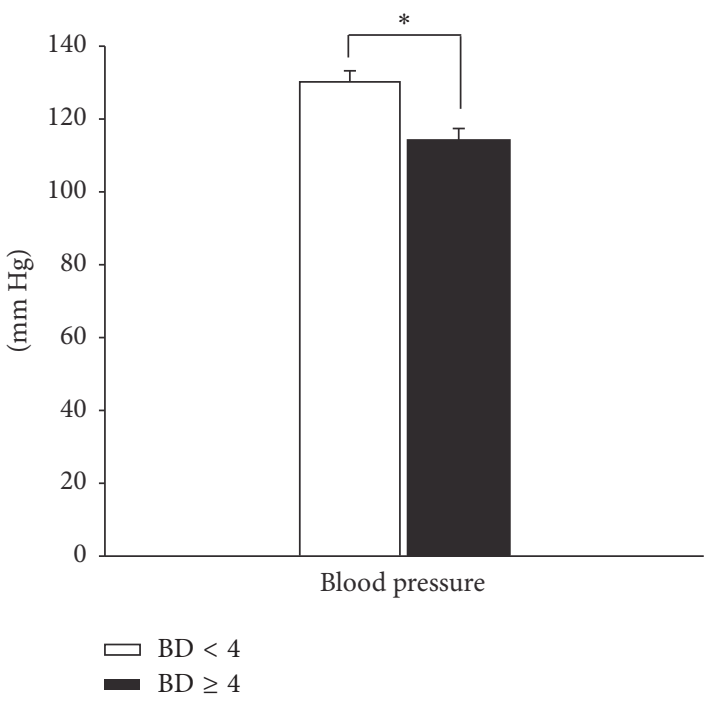

(a)

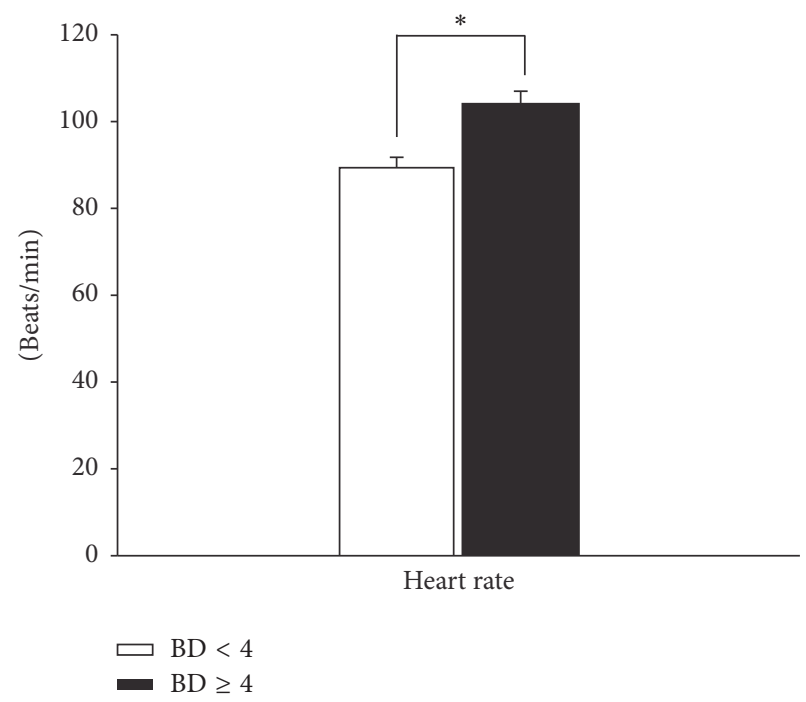

(b)

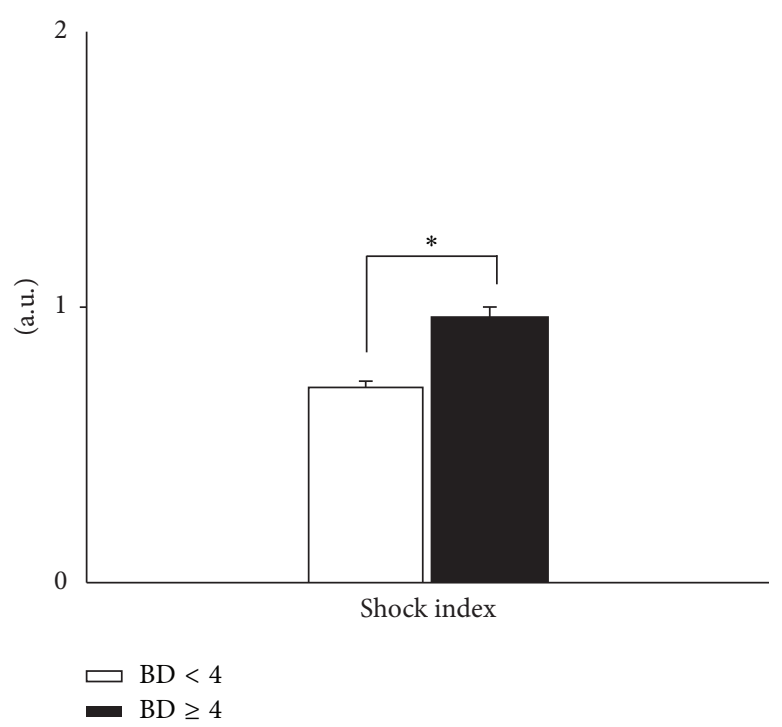

(c)

Figure 2: (a) Differences in (a) admission systolic blood pressure (SBP), (b) admission heart rate (HR), and (c) Shock Index between BD $\geq$ 4 and BD $<4$ subgroups. (a) Admission SBP, (b) admission HR, and (c) Shock Index (HR/SBP) were statistically significantly different in the $\mathrm{BD} \geq 4$ group when compared to the $\mathrm{BD}<4$ group. ${ }^{*} P<0.05$ by Mann-Whitney $U$ test.

admission and over the 7-day course after injury. Accordingly, three plasma samples were obtained within the first $24 \mathrm{~h}$ after injury, including upon arrival as well as daily up to day 7 after injury. To determine difference in levels of inflammatory mediators between the $\mathrm{BD}<4$ and $\mathrm{BD} \geq 4$ subgroups, the biomarker data were analyzed using two-way ANOVA (see Section 2). This extensive analysis revealed that the BD $\geq 4$ group exhibited statistically significantly higher circulating levels of multiple innate-derived (IL-1RA, IL-6, IL8/CCL8, MCP-1/CCL2, IFN- $\alpha$, MIP-1 $\beta /$ CCL4, and TNF- $\alpha$; see Supplementary Figure S1 of the Supplementary Material available online at http://dx.doi.org/10.1155/2016/7950374) and lymphoid-derived (IL-7, IL-4, IFN- $\gamma$, IL-2, IL-13, IL5 , and sIL-2R $\alpha$; Supplementary Figure S2) inflammatory mediators when compared to the $\mathrm{BD}<4$ group. However, both subgroups had fairly similar systemic trajectories, with no statistically significant differences, of MIP- $1 \alpha /$ CCL3, IL$1 \beta$, IL-15, IL-17A, MIG/CXCL9, IL-10, IP-10/CXCL10, GMCSF, and Eotaxin/CCL11.

The aforementioned biomarker analysis suggested that the trauma-induced inflammatory response in patients with admission $\mathrm{BD} \geq 4$ diverges early after injury compared to that of patients with $\mathrm{BD}<4$. Accordingly, we sought to quantify the total inflammatory mediator production across all time points in the first $24 \mathrm{~h}$ by calculating the area under the curve (AUC) in $\mathrm{BD}<4$ and $\mathrm{BD} \geq 4$ subgroups. The AUC was calculated for each biomarker and expressed as fold change between both subgroups (see Section 2). Subsequently, the biomarkers were ranked according to their fold values (from highest to lowest fold change). This analysis showed that 


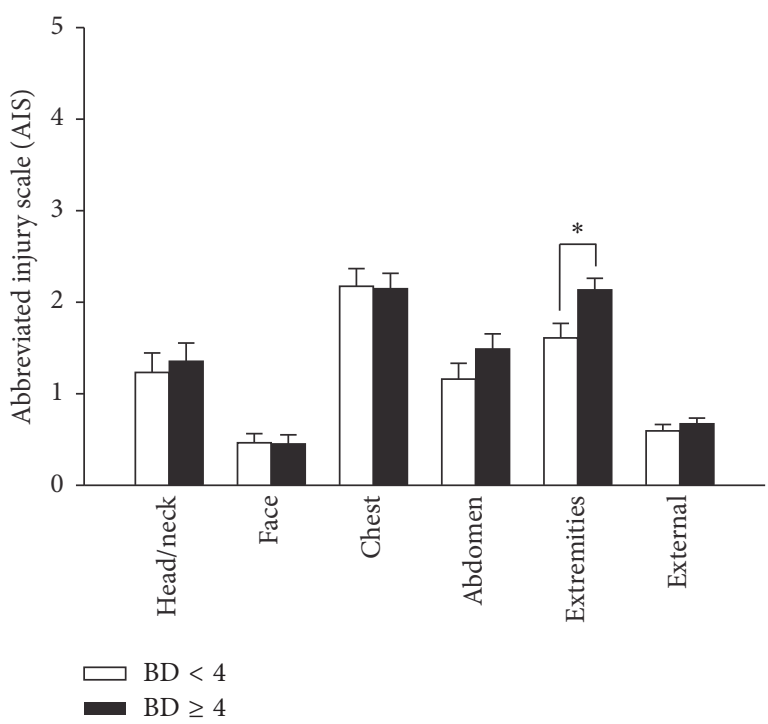

(a)



(b)

FIGURE 3: (a) Abbreviated injury scale (AIS) analysis of injury patterns in $\mathrm{BD} \geq 4$ and $\mathrm{BD}<4$ subgroups. The $\mathrm{BD} \geq 4$ group exhibited greater extremity injury when compared to the $\mathrm{BD}<4$ group. ${ }^{*} P<0.05$ by Mann-Whitney $U$ test. (b) Multiple Organ Dysfunction Score (MODScore) in $\mathrm{BD} \geq 4$ and $\mathrm{BD}<4$ subgroups from days 1 through 7 after injury. The $\mathrm{BD} \geq 4$ group had a statistically significantly higher degree of organ dysfunction from days 2 to 4 after injury compared to the $\mathrm{BD}<4$ group. ${ }^{*} \mathrm{P}<0.05$ by two-way ANOVA.

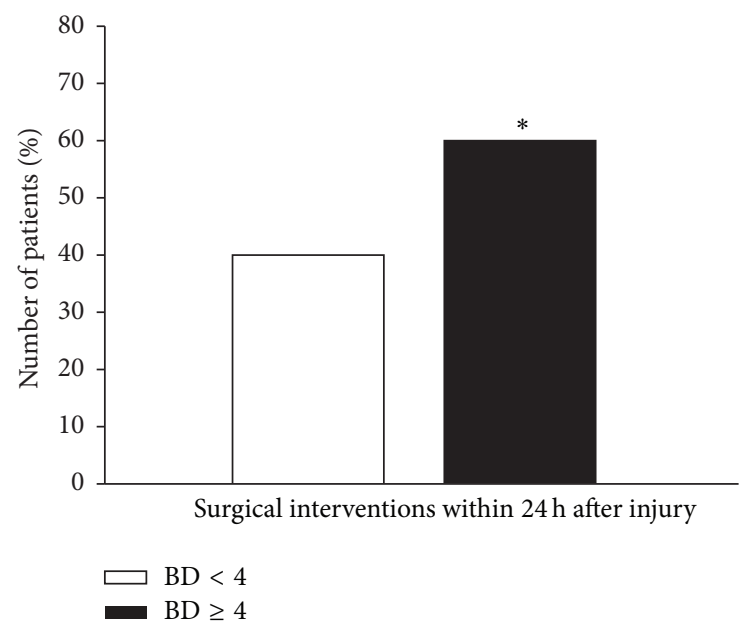

(a)

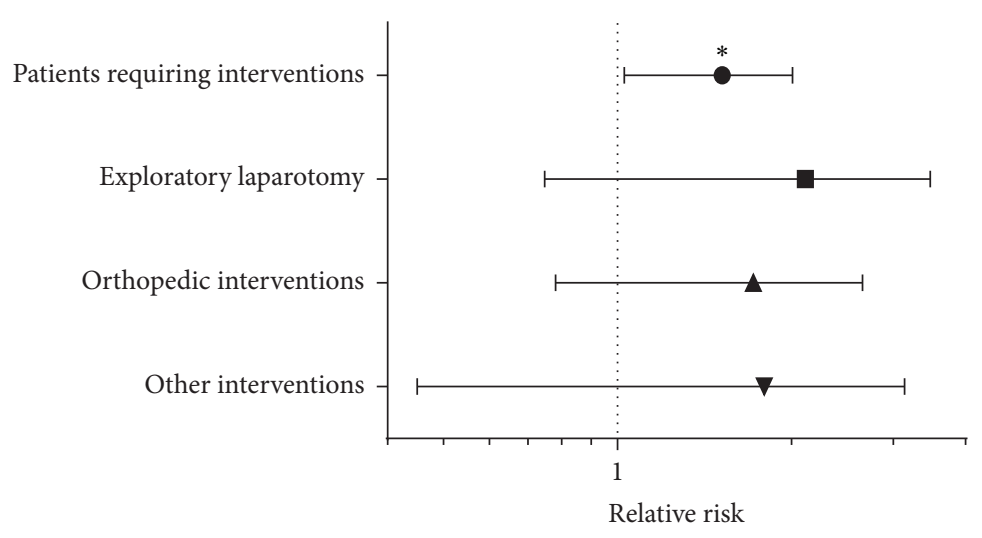

(b)

FIGURE 4: (a) Percentage of patients requiring urgent surgical interventions upon discharge from the trauma bay. $61 \%$ of patients in the BD $\geq 4$ group required immediate surgical interventions compared to $41 \%$ in the $\mathrm{BD}<4$ group. ${ }^{*} P<0.05$ by Chi-square. (b) Relative risk of requiring operative management in the first $24 \mathrm{~h}$ after trauma. Having an admission $\mathrm{BD} \geq 4$ is associated with a 1.5-fold risk of requiring surgical interventions in the first $24 \mathrm{~h}$ after injury. ${ }^{*} \mathrm{RR}=1.5 ; 95 \% \mathrm{CI}[1.056-2.033] ; P<0.05$.

multiple biomarkers of the innate and lymphoid immune systems were elevated over the first $24 \mathrm{~h}$ after injury in the $\mathrm{BD} \geq 4$ group when compared to the $\mathrm{BD}<4$ group (Table 2 ). Interestingly, these biomarkers remained distinct between both groups up to 7 days after injury (Table 3 ).

\subsection{Differential Network Connectivity of Systemic Inflamma-} tion Inferred in $B D \geq 4$ Group. We next hypothesized that these early immune differences between the $\mathrm{BD}<4$ and $\mathrm{BD} \geq$ 4 subgroups could be explained, at least in part, by differential network interconnectivity among inflammatory mediators. This analysis was achieved by generating networks inferred from correlation changes among circulating inflammatory mediators in a time-dependent manner. To create these dynamic networks, we utilized DyNA (see Section 2), an analysis where we essentially calculate correlations among different inflammatory mediators (nodes) and effectively visualize the temporal interconnectivity of these nodes across multiple time points $[17,56,57]$. Figure 5 shows the detailed DyNA results for $\mathrm{BD}<4$ and $\mathrm{BD} \geq 4$ over three different time 
TABLE 2: Summary of the area under the curve (AUC) analysis in the first $24 \mathrm{~h}$ after injury for statistically significantly different inflammatory mediators (by two-way ANOVA) between the $\mathrm{BD}<4$ and $\mathrm{BD} \geq 4$ subgroups.

\begin{tabular}{|c|c|c|c|c|}
\hline Inflammation biomarkers ( $0-24 \mathrm{~h}$ after injury) & $\mathrm{BD} \geq 4(\mathrm{pg} \cdot \mathrm{h} / \mathrm{L})$ & $\mathrm{BD}<4$ (pg.h/L) & Fold change & $P$ value \\
\hline IL-1RA & 2268.0 & 728.3 & 3.1 & $<0.001$ \\
\hline IL-7 & 208.0 & 94.6 & 2.2 & 0.036 \\
\hline IL-8/CCL8 & 222.3 & 103.7 & 2.1 & 0.004 \\
\hline sIL-2R $\alpha$ & 711.2 & 373.8 & 1.9 & 0.005 \\
\hline MCP-1/CCL2 & 2336.7 & 1423.3 & 1.6 & 0.048 \\
\hline
\end{tabular}

TABLE 3: Summary of the area under the curve (AUC) analysis from the time of injury up to day 7 for statistically significantly different inflammatory mediators (by two-way ANOVA) between the $\mathrm{BD}<4$ and the $\mathrm{BD} \geq 4$ subgroups.

\begin{tabular}{|c|c|c|c|c|}
\hline Inflammation biomarkers ( $0 \mathrm{~h}$-day 7 after injury) & $\mathrm{BD} \geq 4$ (pg.h/L) & $\mathrm{BD}<4$ (pg.h/L) & Fold change & $P$ value \\
\hline IL-1RA & 7409.3 & 3731.0 & 2.0 & $<0.001$ \\
\hline IL-5 & 276.1 & 150.4 & 1.8 & 0.005 \\
\hline IL-7 & 880.2 & 479.5 & 1.8 & 0.001 \\
\hline sIL-2R $\alpha$ & 4026.7 & 2356.0 & 1.7 & $<0.001$ \\
\hline IL-6 & 1648.9 & 1022.5 & 1.6 & 0.013 \\
\hline MCP-1/CCL2 & 7254.3 & 4747.9 & 1.5 & $<0.001$ \\
\hline IFN- $\gamma$ & 485.0 & 332.5 & 1.5 & 0.002 \\
\hline IL-13 & 223.5 & 159.9 & 1.4 & 0.002 \\
\hline IL-4 & 466.3 & 342.1 & 1.4 & 0.002 \\
\hline IL-8/CCL8 & 546.7 & 401.6 & 1.4 & 0.045 \\
\hline IFN- $\alpha$ & 575.3 & 430.6 & 1.3 & $<0.001$ \\
\hline IL-2 & 100.8 & 79.6 & 1.3 & 0.037 \\
\hline MIP-1 $\beta / C C L 4$ & 993.0 & 789.2 & 1.3 & 0.029 \\
\hline TNF- $\alpha$ & 115.9 & 94.2 & 1.2 & 0.003 \\
\hline
\end{tabular}

periods following admission to the ED $(0-8 \mathrm{~h}, 8-16 \mathrm{~h}$, and $16-$ $24 \mathrm{~h})$.

This analysis elucidated that the $\mathrm{BD} \geq 4$ group exhibited a higher degree of network interconnectivity ( $\geq 6$ connections) among multiple inflammatory nodes upon admission and up to $16 \mathrm{~h}$ after injury (Figures 5(a) and 5(b)). The traumainduced inflammatory response in the $\mathrm{BD} \geq 4$ group was characterized by both innate immune (IL-1 $\beta$, GM-CSF, MIP$1 \alpha /$ CCL3, MIP-1 $\beta /$ CCL 4, sIL-1R $\alpha$, IFN- $\alpha$, and IFN- $\gamma$ ) and lymphoid (IL-17A, IL-7, IL-4, IL-2, IL-13, and IL-15) pathways. However, the $\mathrm{BD}<4$ group exhibited a lower degree of network interconnectivity over the initial $0-16 \mathrm{~h}$ after injury (Figures 5(d) and 5(e)), with a central network that consisted of IL-4, IL-2, IL-15, MIP-1 $\alpha / C C L 3$, MIP-1 $\beta / C C L 4$, sIL-1R $\alpha$, and IL-1 $\beta$. Interestingly, and by $24 \mathrm{~h}$ after injury, both subgroups' network interconnectivity become more comparable and exhibited multiple sparse networks (Figures 5(c) and 5(f)).

Finally, we sought to assess the global state of the inflammatory networks, by quantifying the total degree of each network present at specific time intervals in both subgroups. The $\mathrm{BD} \geq 4$ group exhibited a higher network density within $8-16$ h after injury when compared to $\mathrm{BD}<4$ group which then declined progressively over the $16-24 \mathrm{~h}$ time period (Figure 6(a)). Interestingly, the inflammation network interconnectivity (see above) and density were in parallel with the actual arterial BD values over the first $24 \mathrm{~h}$ after injury (Figure 6(b)). Taken together, these analyses suggest a higher, coordinated degree of activation of both innate and lymphoid pathways in patients with admission $\mathrm{BD} \geq 4 \mathrm{mEq} / \mathrm{L}$ observed as early within the first $8 \mathrm{~h}$ after injury.

\section{Discussion}

Severe blunt force trauma can induce substantial physiological changes by alteration of the host metabolic pathways and activation of the immune system $[64,65]$. One of the first signs of inadequate tissue perfusion and reduced oxygen delivery is tissue acidosis, which is reflected in serum $\mathrm{pH}$, lactate, arterial BD, and anion gap [66]. Among these parameters, arterial BD has emerged as an important marker in guiding early fluid resuscitation and assessment of shock severity $[44,67,68]$. Despite being sensitive but nonspecific indicator of metabolic acidosis, elevated BD values correlate significantly with in-hospital adverse outcomes [25, 69]. Another key factor that drives outcomes after injury is the magnitude of the accompanying systemic inflammatory response which is largely coordinated by cytokines, chemokines, damageassociated molecular patterns molecules, and free radicals $[13,17]$.

While a properly robust inflammatory response is essential for effective and timely resolution of the injury, immune dysregulation, on the contrary, can impair both the biochemical and physiological functions and predispose patients to follow a complicated clinical course [17, 70]. Indeed, most evidence suggests that either inadequate [71] or overly 


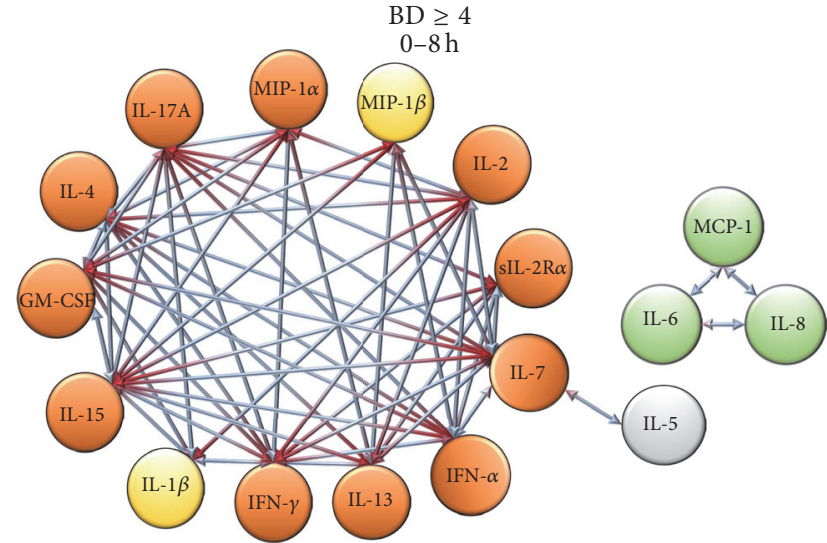

$\begin{array}{ll}1 \text { connection } & \begin{array}{l}4-5 \text { connections } \\ 2-3 \text { connections }\end{array} \geq 6 \text { connections }\end{array}$

(a)

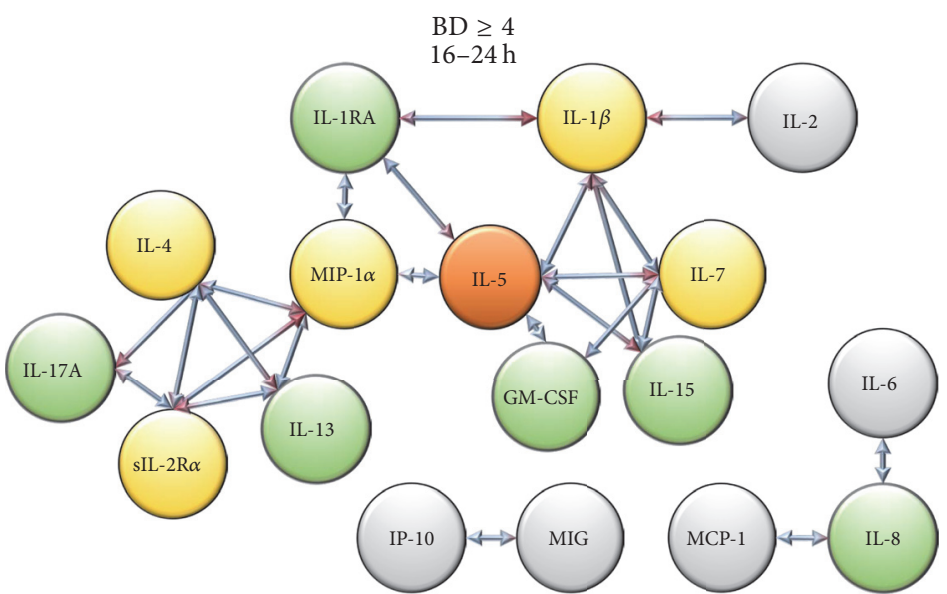
1 connection
2-3 connections

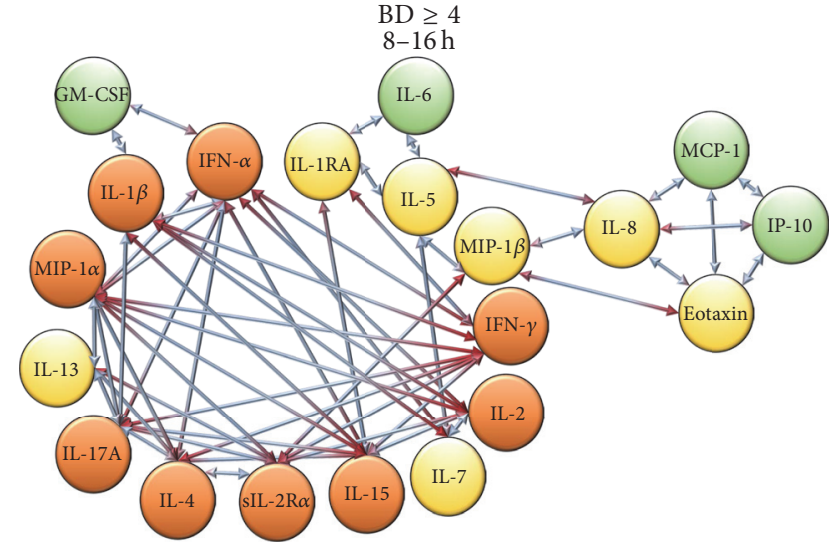

$\begin{array}{ll}1 \text { connection } & \\ 2-3 \text { connections } & 4 \text { connections } \\ \geq 6 \text { connections }\end{array}$

(b)

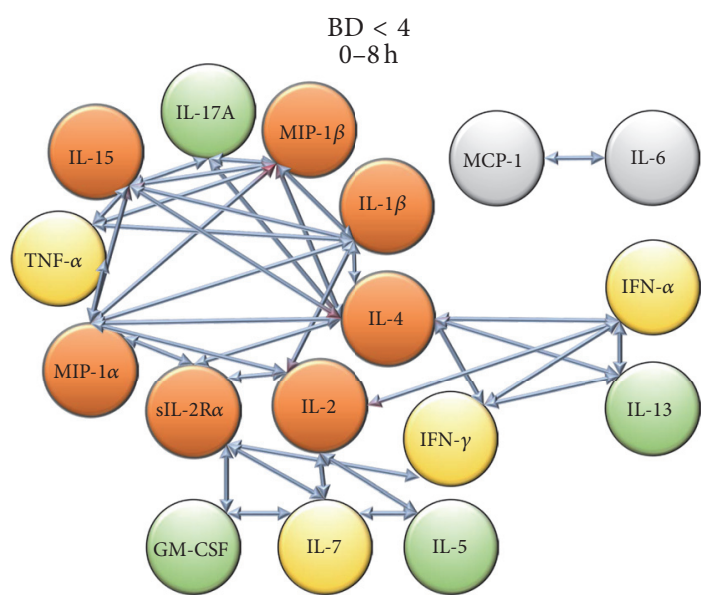

1 connection $4-5$ connections

(f) (d)

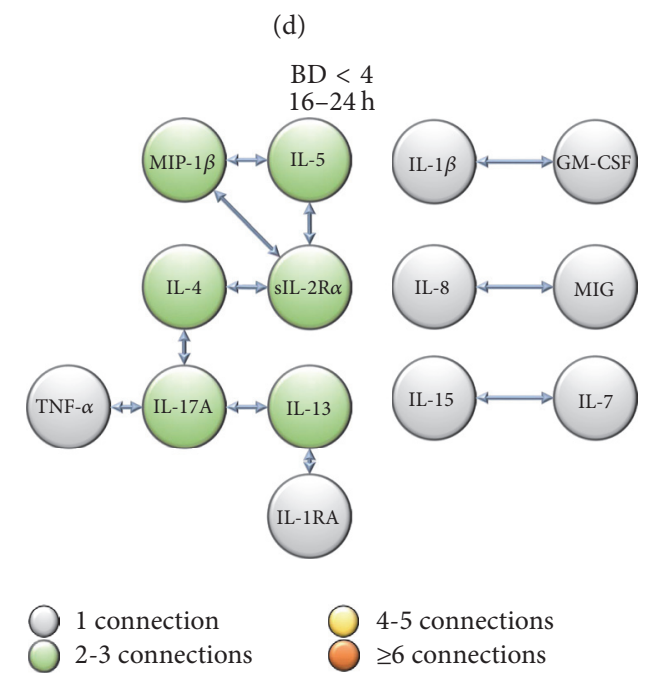

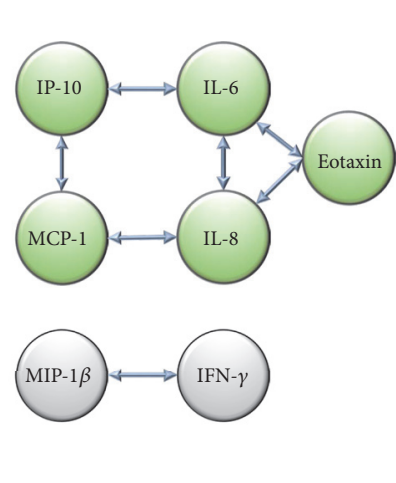

(e)

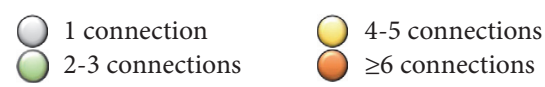

FIGURE 5: Dynamic network analysis (DyNA) of inflammatory mediators in $\mathrm{BD} \geq 4$ and $\mathrm{BD}<4$ subgroups suggests an early differential network connectivity within $16 \mathrm{~h}$ after injury. DyNA at $0-8 \mathrm{~h}$ suggested that IFN- $\alpha /$ sIL-2R $\alpha / \mathrm{MIP}-1 \alpha / \mathrm{IL}-17 \mathrm{~A} / \mathrm{IL}-4 / \mathrm{GM}-\mathrm{CSF} / \mathrm{IL}-7 / \mathrm{IL}-2 / \mathrm{IFN}-$ $\gamma /$ IL-13 were highly connected in the $\mathrm{BD} \geq 4$ group (a) while the $\mathrm{BD}<4$ group (d) exhibited a lesser degree of connected nodes: MIP- $1 \alpha /$ sIL$2 \mathrm{R} \alpha / \mathrm{MIP}-1 \beta / \mathrm{IL}-4 / \mathrm{IL}-1 \beta / \mathrm{IL}-2 / \mathrm{IL}-15$. DyNA at $8-16 \mathrm{~h}$ suggested that the $\mathrm{BD} \geq 4$ group (b) retained the connectivity among inflammatory mediators, whereas the $\mathrm{BD}<4$ group (e) continued to exhibit a lesser degree of connections. DyNA at $16-24 \mathrm{~h}$ suggested that the $\mathrm{BD} \geq 4$ group (c) exhibited a substantial reduction of network connectivity to a level similar to BD $<4$ group (f). 


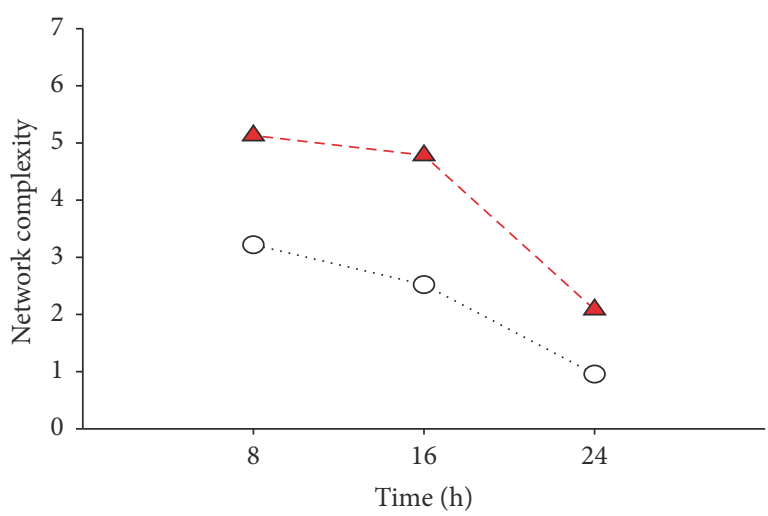

(a)

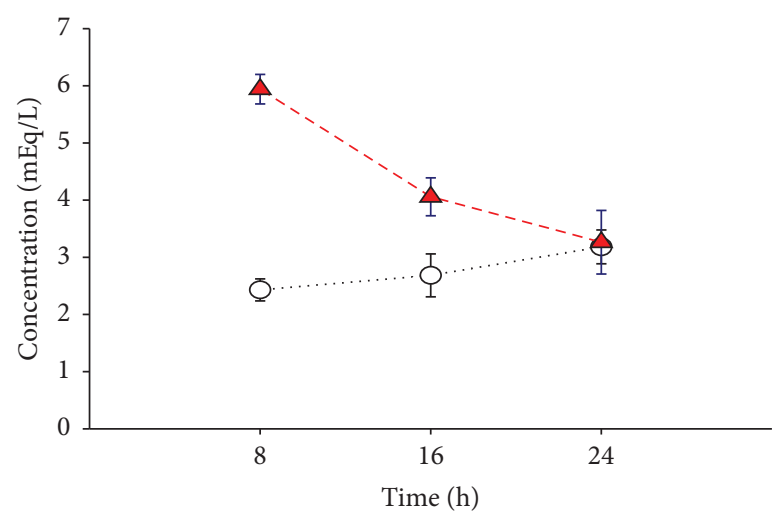

(b)

Figure 6: (a) Network complexity differs between the $\mathrm{BD} \geq 4$ and $\mathrm{BD}<4$ subgroups over the first $24 \mathrm{~h}$ after injury. The $\mathrm{BD} \geq 4$ group exhibited a higher network density at $8 \mathrm{~h}$ and $16 \mathrm{~h}$ after injury which progressively decreased to similar levels of BD $<4$ group at $24 \mathrm{~h}$ after injury. (b) Arterial BD levels within $24 \mathrm{~h}$ after injury. BD levels in both $\mathrm{BD} \geq 4$ and $\mathrm{BD}<4$ subgroups mirror the density of their corresponding inflammatory networks.

exuberant [11] inflammation can drive the pathobiology of trauma and subsequent processes such as persistent critical illness. In view of this, we hypothesized that early, differential immune/inflammatory mechanisms are set in motion by the posttraumatic metabolic acidosis, in a manner associated with distant differential clinical outcomes.

By using a BD cutoff of below versus above $4 \mathrm{mEq} / \mathrm{L}$, we were able to identify and compare two blunt trauma groups with regard to their early dynamic networks of systemic inflammation as well as in-hospital complications as an endpoint of posttraumatic outcome. We initially confirmed key prior observations regarding the association of elevated admission BD with adverse outcomes, namely, significantly greater requirement for blood transfusion, longer ICU and hospital stay, and higher degree of MOD. A key observation from this analysis was that the $\mathrm{BD} \geq 4$ group had a greater likelihood of requiring operative intervention within the first $24 \mathrm{~h}$ after injury.

The $\mathrm{BD} \geq 4$ and $\mathrm{BD}<4$ groups did not differ with regard to their overall injury severity, suggesting that the injury severity alone does not appear to be the only driver of metabolic derangement after trauma. Rather, we suggest that the intensity of activation of multiple immune/inflammatory pathways, set in motion early following injury, could drive divergent clinical trajectory in otherwise similarly injured patients. In support of this notion, we have previously shown that distinct, dynamic circulating inflammatory patterns and networks emerge early after trauma, which were associated with in-hospital complications such as nosocomial infection and MOD [17]. In the current study, both groups exhibited a similar elevation in MODScore initially; the degree of MOD persisted in the $\mathrm{BD} \geq 4$ group but resolved gradually over the 7-day time course in the $\mathrm{BD}<4$ group, paralleling the divergent systemic inflammatory responses observed in these patient groups. We speculate that these MOD-based immune trajectories are not solely due to metabolic derangement and that other factors such as the injury patterns, specifically extremity injury and subsequent requirement for operative intervention or transfusions, may contribute as well to the early immune divergence after injury.

Analysis of the biomarker patterns showed that the two groups diverged based on IL-6, MCP-1/CCL2, IL-8/CCL8, and IL-1RA as early as we could measure upon admission, correlating with elevated MODScores observed after day 1 and up to day 4 after injury. Prior studies have suggested the utility of elevated circulating inflammation biomarkers, in particular IL-6, as early predictors of MOD in trauma patients $[16,72]$. Furthermore, we have previously showed that the chemokine MCP-1/CCL2 plays a central role in driving hepatocyte IL-6 production, as well as systemic IL-6 and outcomes in blunt trauma patients $[17,57,73]$.

Though these mediators have been appreciated as being central to the acute inflammatory response, computational modeling has allowed for both their integration into a systems-based process and raising the potential for novel translational applications targeting nonintuitive central mediators as defined by modeling. In silico inference of dynamic network interconnectivity and complexity suggests a bifurcation of well-regulated versus dysregulated inflammation in $\mathrm{BD}<4$ and $\mathrm{BD} \geq 4$ groups, respectively, early after injury. These findings suggest that the overall magnitude of the inflammatory response is greater in the $\mathrm{BD} \geq 4$ group and that additional immune components are engaged early in patients subsequent to injury that drives metabolic derangement. Importantly, these in silico-defined trajectories of inflammation mimic the clinical trajectories of MOD over the 7 days in both groups, including normalization by $\sim 24 \mathrm{~h}$ that is associated with a convergence of $\mathrm{BD}$ values in both groups. This normalization may be driven by resuscitation and other supportive measures.

We recognize that there are several limitations in our study. First, this study was performed at a single, Level I trauma center and thus may not be generalizable or pertinent to other centers with differing admission demographics, injury characteristics, or management practices. This issue warrants additional, similar studies in other trauma centers to 
validate the results suggested from the current study. Another important limitation of this study is the potential impact of blood transfusion and surgical interventions on the temporal dynamics of the inflammatory response. We note that these interventions are by necessity an intrinsic element of clinical care for management of trauma patients with evidence of hypovolemic shock. We suggest that these patients who received this type of interventions reflect patients with hemodynamic and metabolic instability and that by excluding these patients we will be missing the opportunity to capture the early dynamic changes of the inflammatory response. Moreover, the number of inflammatory biomarkers analyzed was limited to the number of analyte we could measure using commercially available Luminex bead sets. Further future studies examining a larger panel of inflammatory biomarkers are suggested. Finally, we note that DyNA lacks mechanistic insight; however, it can be used to understand abstract key features and interactions of the trauma-induced inflammatory response.

\section{Conclusions}

The current study demonstrates the presence of a differential, distinct immune network in the early postinjury phase in $\mathrm{BD}$ $<4$ and $\mathrm{BD} \geq 4$ trauma patients which significantly correlate with later divergent clinical outcomes. We suggest that an approach combining extensive early biomarker sampling and computational data-driven modeling can be used as a framework for patient stratification and outcome prediction in the setting of critical illness.

\section{Abbreviations}

$\begin{array}{ll}\text { MOD: } & \text { Multiple organ dysfunction } \\ \text { ICU: } & \text { Intensive Care Unit } \\ \text { ED: } & \text { Emergency Department } \\ \text { DyNA: } & \text { Dynamic network analysis } \\ \text { IL: } & \text { Interleukin } \\ \text { IFN: } & \text { Interferon } \\ \text { MCP-1/CCL2: } & \text { Monocyte chemotactic protein-1 } \\ \text { MIG/CXCL-9: } & \text { Monokine inducible by interferon- } \gamma \\ \text { MIP-1 } \alpha / C C L-3: & \text { Macrophage inflammatory protein- } 1 \alpha .\end{array}$

\section{Disclosure}

Timothy R. Billiar and Rami A. Namas are co-senior authors.

\section{Competing Interests}

The authors declare that they have no competing interests.

\section{Acknowledgments}

This work was supported by the National Institutes of Health (Grant P50-GM-53789) and the Ruth L. Kirschstein National Research Service Award T32-GM-008516-21.

\section{References}

[1] R. E. Falcone, S. A. Santanello, M. A. Schulz, J. Monk, B. Satiani, and L. C. Carey, "Correlation of metabolic acidosis with outcome following injury and its value as a scoring tool," World Journal of Surgery, vol. 17, no. 5, pp. 575-579, 1993.

[2] C. M. Dunham, J. H. Siegel, L. Weireter et al., "Oxygen debt and metabolic acidemia as quantitative predictors of mortality and the severity of the ischemic insult in hemorrhagic shock," Critical Care Medicine, vol. 19, no. 2, pp. 231-243, 1991.

[3] L. J. Kaplan and J. A. Kellum, "Comparison of acid-base models for prediction of hospital mortality after trauma," Shock, vol. 29, no. 6, pp. 662-666, 2008.

[4] J. A. Kellum, M. Song, and J. Li, "Science review: extracellular acidosis and the immune response: clinical and physiologic implications," Critical Care, vol. 8, no. 5, pp. 331-336, 2004.

[5] P. J. Neligan and D. Baranov, "Trauma and aggressive homeostasis management," Anesthesiology Clinics, vol. 31, no. 1, pp. 21-39, 2013.

[6] H. J. Adrogué and N. E. Madias, "Management of lifethreatening acid-base disorders (First of Two Parts)," The New England Journal of Medicine, vol. 338, no. 1, pp. 26-34, 1998.

[7] O. Blow, L. Magliore, J. A. Claridge, K. Butler, and J. S. Young, "The golden hour and the silver day: detection and correction of occult hypoperfusion within 24 hours improves outcome from major trauma," Journal of Trauma-Injury, Infection and Critical Care, vol. 47, no. 5, pp. 964-969, 1999.

[8] J. A. Kellum, M. Song, and E. Almasri, "Hyperchloremic acidosis increases circulating inflammatory molecules in experimental sepsis," Chest, vol. 130, no. 4, pp. 962-967, 2006.

[9] A. Lardner, "The effects of extracellular $\mathrm{pH}$ on immune function," Journal of Leukocyte Biology, vol. 69, no. 4, pp. 522-530, 2001.

[10] D. Rixen and J. H. Siegel, "Metabolic correlates of oxygen debt predict posttrauma early acute respiratory distress syndrome and the related cytokine response," Journal of Trauma-Injury, Infection and Critical Care, vol. 49, no. 3, pp. 392-403, 2000.

[11] C. Neunaber, C. Zeckey, H. Andruszkow et al., "Immunomodulation in polytrauma and polymicrobial sepsis-where do we stand?" Recent Patents on Inflammation and Allergy Drug Discovery, vol. 5, no. 1, pp. 17-25, 2011.

[12] C. Nathan and A. Ding, "Nonresolving inflammation," Cell, vol. 140, no. 6, pp. 871-882, 2010.

[13] R. A. Namas, Q. Mi, R. Namas et al., "Insights into the role of chemokines, damage-associated molecular patterns, and lymphocyte-derived mediators from computational models of trauma-induced inflammation," Antioxidants and Redox Signaling, vol. 23, no. 17, pp. 1370-1387, 2015.

[14] J. Cohen, “The immunopathogenesis of sepsis," Nature, vol. 420, no. 6917, pp. 885-891, 2002.

[15] G. V. Bochicchio, L. M. Napolitano, M. Joshi et al., "Persistent systemic inflammatory response syndrome is predictive of nosocomial infection in trauma," Journal of Trauma-Injury, Infection and Critical Care, vol. 53, no. 2, pp. 245-251, 2002.

[16] K. M. Jastrow III, E. A. Gonzalez, M. F. McGuire et al., "Early cytokine production risk stratifies trauma patients for multiple organ failure," Journal of the American College of Surgeons, vol. 209, no. 3, pp. 320-331, 2009.

[17] R. A. Namas, Y. Vodovotz, K. Almahmoud et al., "Temporal patterns of circulating inflammation biomarker networks differentiate susceptibility to nosocomial infection following blunt 
trauma in humans," Annals of Surgery, vol. 263, no. 1, pp. 191-198, 2016.

[18] E. Hasenboehler, A. Williams, I. Leinhase et al., "Metabolic changes after polytrauma: an imperative for early nutritional support," World Journal of Emergency Surgery, vol. 1, no. 1, article 29, 2006.

[19] S. A. Tisherman, P. Barie, F. Bokhari et al., "Clinical practice guideline: endpoints of resuscitation," Journal of TraumaInjury, Infection and Critical Care, vol. 57, no. 4, pp. 898-912, 2004.

[20] H. M. A. Kaafarani and G. C. Velmahos, "Damage control resuscitation in trauma," Scandinavian Journal of Surgery, vol. 103, no. 2, pp. 81-88, 2014.

[21] E. H. Kincaid, P. R. Miller, J. W. Meredith, N. Rahman, and M. C. Chang, "Elevated arterial base deficit in trauma patients: a marker of impaired oxygen utilization," Journal of the American College of Surgeons, vol. 187, no. 4, pp. 384-392, 1998.

[22] M. S. Englehart and M. A. Schreiber, "Measurement of acidbase resuscitation endpoints: lactate, base deficit, bicarbonate or what?" Current Opinion in Critical Care, vol. 12, no. 6, pp. 569-574, 2006.

[23] L. Paladino, R. Sinert, D. Wallace, T. Anderson, K. Yadav, and S. Zehtabchi, "The utility of base deficit and arterial lactate in differentiating major from minor injury in trauma patients with normal vital signs," Resuscitation, vol. 77, no. 3, pp. 363-368, 2008.

[24] J.-F. Ouellet, D. J. Roberts, C. Tiruta et al., "Admission base deficit and lactate levels in Canadian patients with blunt trauma: are they useful markers of mortality?" Journal of Trauma and Acute Care Surgery, vol. 72, no. 6, pp. 1532-1535, 2012.

[25] J. H. Siegel, A. I. Rivkind, S. Dalal, and S. Goodarzi, "Early physiologic predictors of injury severity and death in blunt multiple trauma," Archives of Surgery, vol. 125, no. 4, pp. 498$508,1990$.

[26] Y. Levi, I. Jeroukhimov, K. Peleg, M. Rozenfeld, I. Shavit, and E. Kozer, "Base excess as a predictor for injury severity in pediatric trauma patients," Journal of Emergency Medicine, vol. 45, no. 4, pp. 496-501, 2013.

[27] D. Rixen and J. H. Siegel, "Bench-to-bedside review: oxygen debt and its metabolic correlates as quantifiers of the severity of hemorrhagic and posttraumatic shock," Critical Care, vol. 9, no. 5, pp. 441-453, 2005.

[28] M. C. Chang, E. J. Rutherford, and J. A. Morris Jr., "Base deficit as a guide to injury severity and volume resuscitation," Journal of the Tennessee Medical Association, vol. 86, no. 2, pp. 59-61, 1993.

[29] M. K. Ziglar, "Application of base deficit in resuscitation of trauma patients," International Journal of Trauma Nursing, vol. 6, no. 3, p. 81, 2000.

[30] I. Smith, P. Kumar, S. Molloy et al., "Base excess and lactate as prognostic indicators for patients admitted to intensive care," Intensive Care Medicine, vol. 27, no. 1, pp. 74-83, 2001.

[31] T. C. Jansen, J. Van Bommel, F. J. Schoonderbeek et al., "Early lactate-guided therapy in intensive care unit patients: a multicenter, open-label, randomized controlled trial," American Journal of Respiratory and Critical Care Medicine, vol. 182, no. 6, pp. 752-761, 2010.

[32] E. J. Rutherford, J. A. Morris Jr., G. W. Reed, and K. S. Hall, "Base deficit stratifies mortality and determines therapy," Journal of Trauma-Injury, Infection and Critical Care, vol. 33, no. 3, pp. 417-423, 1992.
[33] A. J. Botha, F. A. Moore, E. E. Moore, V. M. Peterson, and A. W. Goode, "Base deficit after major trauma directly relates to neutrophil CD11b expression: a proposed mechanism of shockinduced organ injury," Intensive Care Medicine, vol. 23, no. 5, pp. 504-509, 1997.

[34] A. I. A. Shane, W. Robert, K. Arthur, M. Patson, and G. Moses, "Acid-base disorders as predictors of early outcomes in major trauma in a resource limited setting: an observational prospective study," The Pan African Medical Journal, vol. 17, article 2, 2014.

[35] D. W. Callaway, N. I. Shapiro, M. W. Donnino, C. Baker, and C. L. Rosen, "Serum lactate and base deficit as predictors of mortality in normotensive elderly blunt trauma patients," The Journal of Trauma, vol. 66, no. 4, pp. 1040-1044, 2009.

[36] M. Surbatovic, S. Radakovic, M. Jevtic et al., "Predictive value of serum bicarbonate, arterial base deficit/excess and SAPS III score in critically ill patients," General Physiology and Biophysics, vol. 28, pp. 271-276, 2009.

[37] M. J. Vandromme, R. L. Griffin, J. A. Weinberg, L. W. Rue III, and J. D. Kerby, "Lactate is a better predictor than systolic blood pressure for determining blood requirement and mortality: could prehospital measures improve trauma triage?" Journal of the American College of Surgeons, vol. 210, no. 5, pp. 861-867, 2010.

[38] B. M. Fuller and R. P. Dellinger, "Lactate as a hemodynamic marker in the critically ill," Current Opinion in Critical Care, vol. 18, no. 3, pp. 267-272, 2012.

[39] S. Cheddie, D. J. J. Muckart, and T. C. Hardcastle, "Base deficit as an early marker of coagulopathy in trauma," South African Journal of Surgery, vol. 51, no. 3, pp. 88-90, 2013.

[40] M. Mofidi, A. Hasani, and N. Kianmehr, "Determining the accuracy of base deficit in diagnosis of intra-abdominal injury in patients with blunt abdominal trauma," American Journal of Emergency Medicine, vol. 28, no. 8, pp. 933-936, 2010.

[41] C. Cassidy and J. Marcher, "Base deficit: an indicator of tissue hypoperfusion," International Journal of Trauma Nursing, vol. 1, no. 4, pp. 108-112, 1995.

[42] V. Sharma, T. Shanti Devi, R. Sharma et al., "Arterial pH, bicarbonate levels and base deficit at presentation as markers of predicting mortality in acute pancreatitis: a single-centre prospective study," Gastroenterology Report, vol. 2, no. 3, pp. 226-231, 2014.

[43] A. L. Neville, D. Nemtsev, R. Manasrah, S. D. Bricker, and B. A. Putnam, "Mortality risk stratification in elderly trauma patients based on initial arterial lactate and base deficit levels," American Surgeon, vol. 77, no. 10, pp. 1337-1341, 2011.

[44] J. W. Davis, S. R. Shackford, and T. L. Holbrook, "Base deficit as a sensitive indicator of compensated shock and tissue oxygen utilization," Surgery Gynecology \& Obstetrics, vol. 173, no. 6, pp. 473-476, 1991.

[45] S. P. Baker, B. O’Neill, W. Haddon Jr., and W. B. Long, "The injury severity score: a method for describing patients with multiple injuries and evaluating emergency care," Journal of Trauma, vol. 14, no. 3, pp. 187-196, 1974.

[46] T. A. Gennarelli and E. Wodzin, "AIS 2005: a contemporary injury scale," Injury, vol. 37, no. 12, pp. 1083-1091, 2006.

[47] J. C. Marshall, D. J. Cook, N. V. Christou, G. R. Bernard, C. L. Sprung, and W. J. Sibbald, "Multiple organ dysfunction score: a reliable descriptor of a complex clinical outcome," Critical Care Medicine, vol. 23, no. 10, pp. 1638-1652, 1995.

[48] J. P. Tourtier, D. Jost, and L. Domanski, "Shock index: a simple clinical parameter for mortality risk assessment in trauma?" 
Journal of Trauma and Acute Care Surgery, vol. 73, no. 3, pp. 780-781, 2012.

[49] J. W. Davis, K. L. Kaups, and S. N. Parks, "Effect of alcohol on the utility of base deficit in trauma," Journal of Trauma, vol. 43, no. 3, pp. 507-510, 1997.

[50] M. L. Gustafson, S. Hollosi, J. T. Chumbe, D. Samanta, A. Modak, and A. Bethea, "The effect of ethanol on lactate and base deficit as predictors of morbidity and mortality in trauma," The American Journal of Emergency Medicine, vol. 33, no. 5, pp. 607613, 2015.

[51] C. M. Dunham, L. A. Watson, and C. Cooper, "Base deficit level indicating major injury is increased with ethanol," Journal of Emergency Medicine, vol. 18, no. 2, pp. 165-171, 2000.

[52] G. Kasotakis, A. Sideris, Y. Yang et al., "Aggressive early crystalloid resuscitation adversely affects outcomes in adult blunt trauma patients: an analysis of the Glue Grant database," Journal of Trauma and Acute Care Surgery, vol. 74, no. 5, pp. 1215-1222, 2013.

[53] L. S. Chawla, A. Nader, T. Nelson et al., "Utilization of base deficit and reliability of base deficit as a surrogate for serum lactate in the peri-operative setting," BMC Anesthesiology, vol. 10, article 16, 2010.

[54] R. Sinert, S. Zehtabchi, C. Bloem, and M. Lucchesi, "Effect of normal saline infusion on the diagnostic utility of base deficit in identifying major injury in trauma patients," Academic Emergency Medicine, vol. 13, no. 12, pp. 1269-1274, 2006.

[55] B. J. Baron, R. H. Sinert, A. K. Sinha, M. C. Buckley, G. W. Shaftan, and T. M. Scalea, "Effects of traditional versus delayed resuscitation on serum lactate and base deficit," Resuscitation, vol. 43, no. 1, pp. 39-46, 1999.

[56] Q. Mi, G. Constantine, C. Ziraldo et al., "A dynamic view of trauma/hemorrhage-induced inflammation in mice: principal drivers and networks," PLoS ONE, vol. 6, no. 5, Article ID e19424, 2011.

[57] C. Ziraldo, Y. Vodovotz, R. A. Namas et al., "Central role for MCP-1/CCL2 in injury-induced inflammation revealed by in vitro, in silico, and clinical studies," PLoS ONE, vol. 8, no. 12, Article ID e79804, 2013.

[58] R. L. Gruen, B. J. Gabbe, H. T. Stelfox, and P. A. Cameron, "Indicators of the quality of trauma care and the performance of trauma systems," The British Journal of Surgery, vol. 99, no. 1, pp. 97-104, 2012.

[59] J. Szopinski, K. Kusza, and M. Semionow, "Microcirculatory responses to hypovolemic shock," Journal of Trauma-Injury, Infection and Critical Care, vol. 71, no. 6, pp. 1779-1788, 2011.

[60] M. Kaiser, P. Ahearn, X.-M. Nguyen et al., "Early predictors of the need for emergent surgery to control hemorrhage in hypotensive trauma patients," American Surgeon, vol. 75, no. 10, pp. 986-990, 2009.

[61] S. Germanos, S. Gourgiotis, C. Villias, M. Bertucci, N. Dimopoulos, and N. Salemis, "Damage control surgery in the abdomen: an approach for the management of severe injured patients," International Journal of Surgery, vol. 6, no. 3, pp. 246252, 2008.

[62] F. D. Brenneman, D. A. Redelmeier, B. R. Boulanger, B. A. McLellan, and J. P. Culhane, "Long-term outcomes in blunt trauma: who goes back to work?" Journal of Trauma-Injury, Infection and Critical Care, vol. 42, no. 5, pp. 778-781, 1997.

[63] C. von Rüden, A. Woltmann, M. Röse et al., "Outcome after severe multiple trauma: a retrospective analysis," Journal of Trauma Management and Outcomes, vol. 7, no. 1, article 4, 2013.
[64] L. D. Plank and G. L. Hill, "Energy balance in critical illness," Proceedings of the Nutrition Society, vol. 62, no. 2, pp. 545-552, 2003.

[65] R. D. Griffiths, C. J. Hinds, and R. A. Little, "Manipulating the metabolic response to injury," British Medical Bulletin, vol. 55, no. 1, pp. 181-195, 1999.

[66] A. S. Santibanez-Gallerani, A. E. Barber, S. J. Williams, B. S. Y. Zhao, and G. T. Shires, "Improved survival with early fluid resuscitation following hemorrhagic shock," World Journal of Surgery, vol. 25, no. 5, pp. 592-597, 2001.

[67] J. W. Davis, K. L. Kaups, and S. N. Parks, "Base deficit is superior to $\mathrm{pH}$ in evaluating clearance of acidosis after traumatic shock," Journal of Trauma-Injury, Infection and Critical Care, vol. 44, no. 1, pp. 114-118, 1998.

[68] J. W. Davis, S. R. Shackford, R. C. Mackersie, and D. B. Hoyt, "Base deficit as a guide to volume resuscitation," Journal of Trauma, vol. 28, no. 10, pp. 1464-1467, 1988.

[69] J. W. Davis, S. N. Parks, K. L. Kaups, H. E. Gladen, and S. O'Donnell-Nicol, "Admission base deficit predicts transfusion requirements and risk of complications," Journal of TraumaInjury, Infection and Critical Care, vol. 41, no. 5, pp. 769-774, 1996.

[70] B. Maier, R. Lefering, M. Lehnert et al., "Early versus late onset of multiple organ failure is associated with differing patterns of plasma cytokine biomarker expression and outcome after severe trauma," Shock, vol. 28, no. 6, pp. 668-674, 2007.

[71] R. Namas, A. Ghuma, A. Torres et al., "An adequately robust early TNF- $\alpha$ response is a hallmark of survival following trauma/hemorrhage," PLoS ONE, vol. 4, no. 12, article e8406, 2009.

[72] J. Cuschieri, E. Bulger, V. Schaeffer et al., "Early elevation in random plasma IL-6 after severe injury is associated with development of organ failure," Shock, vol. 34, no. 4, pp. 346-351, 2010.

[73] K. Almahmoud, R. A. Namas, A. M. Zaaqoq et al., "Prehospital hypotension is associated with altered inflammation dynamics and worse outcomes following blunt trauma in humans," Critical Care Medicine, vol. 43, no. 7, pp. 1395-1404, 2015. 


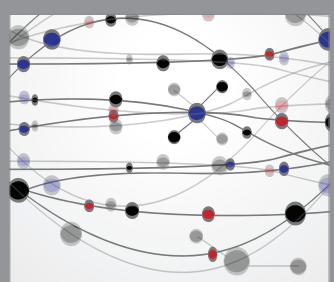

The Scientific World Journal
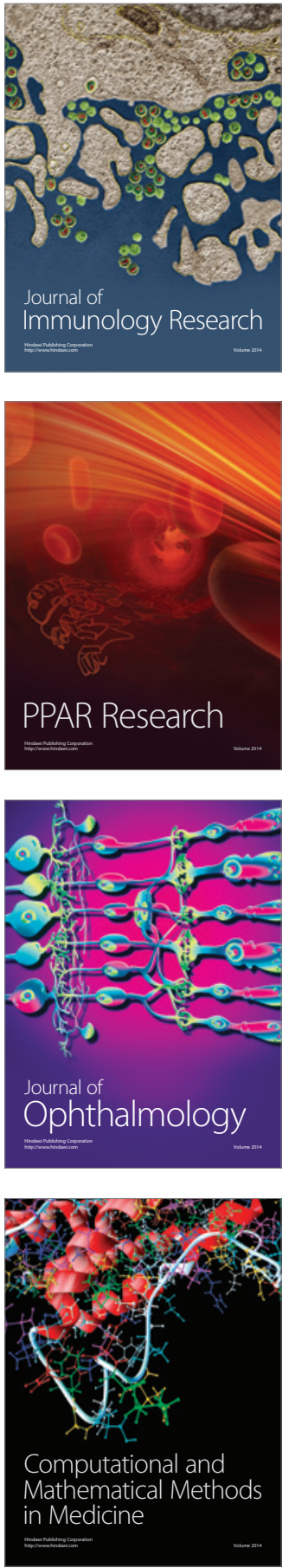

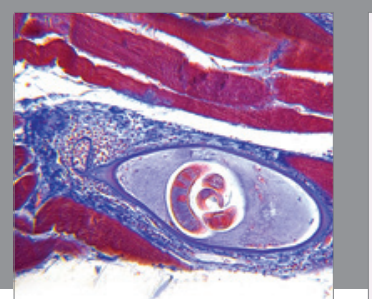

Gastroenterology Research and Practice

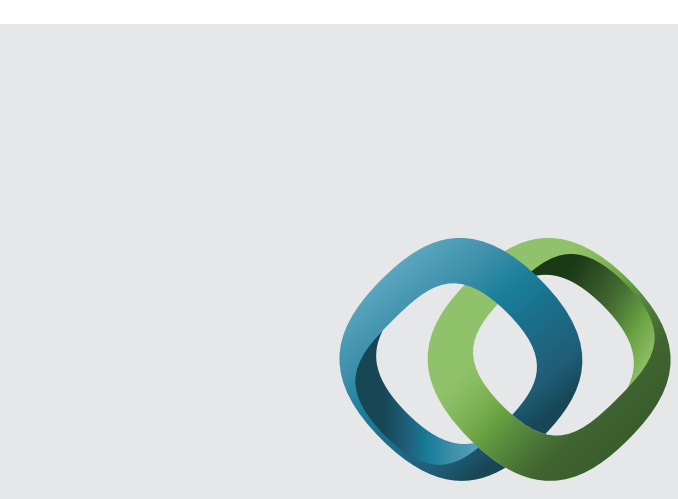

\section{Hindawi}

Submit your manuscripts at

http://www.hindawi.com
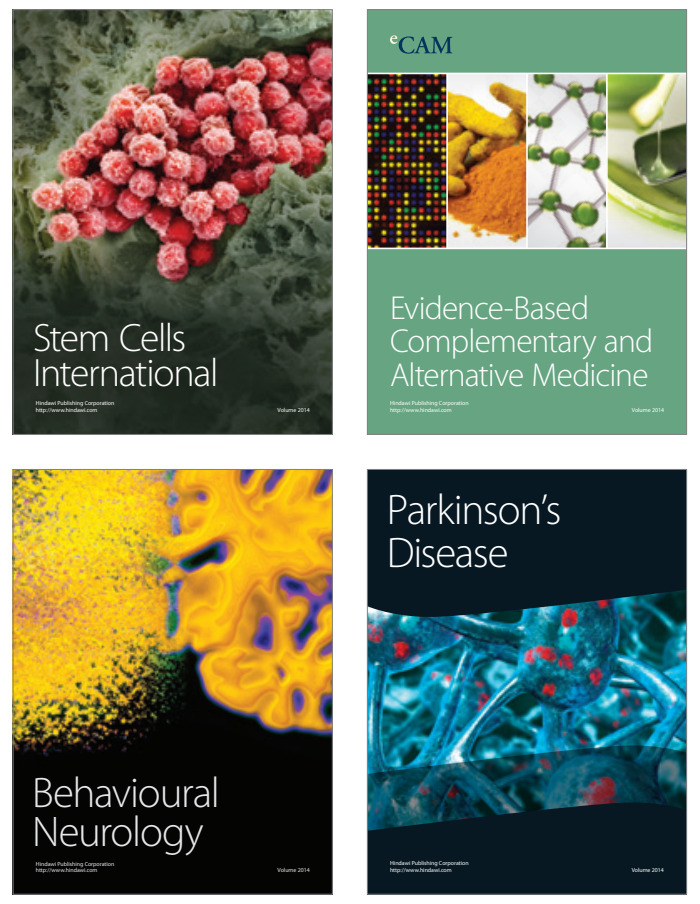
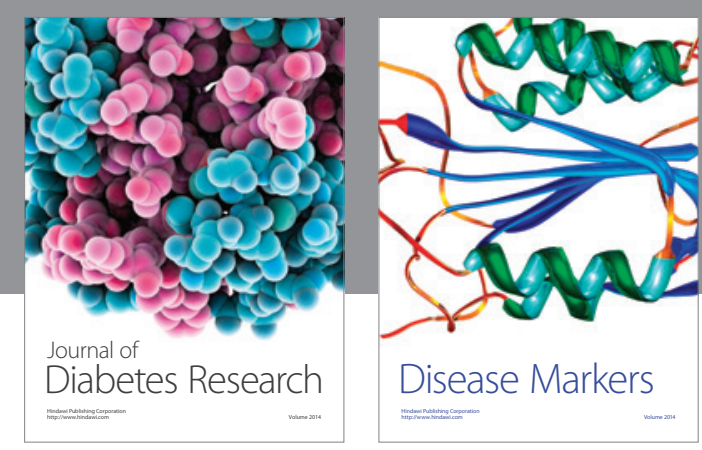

Disease Markers
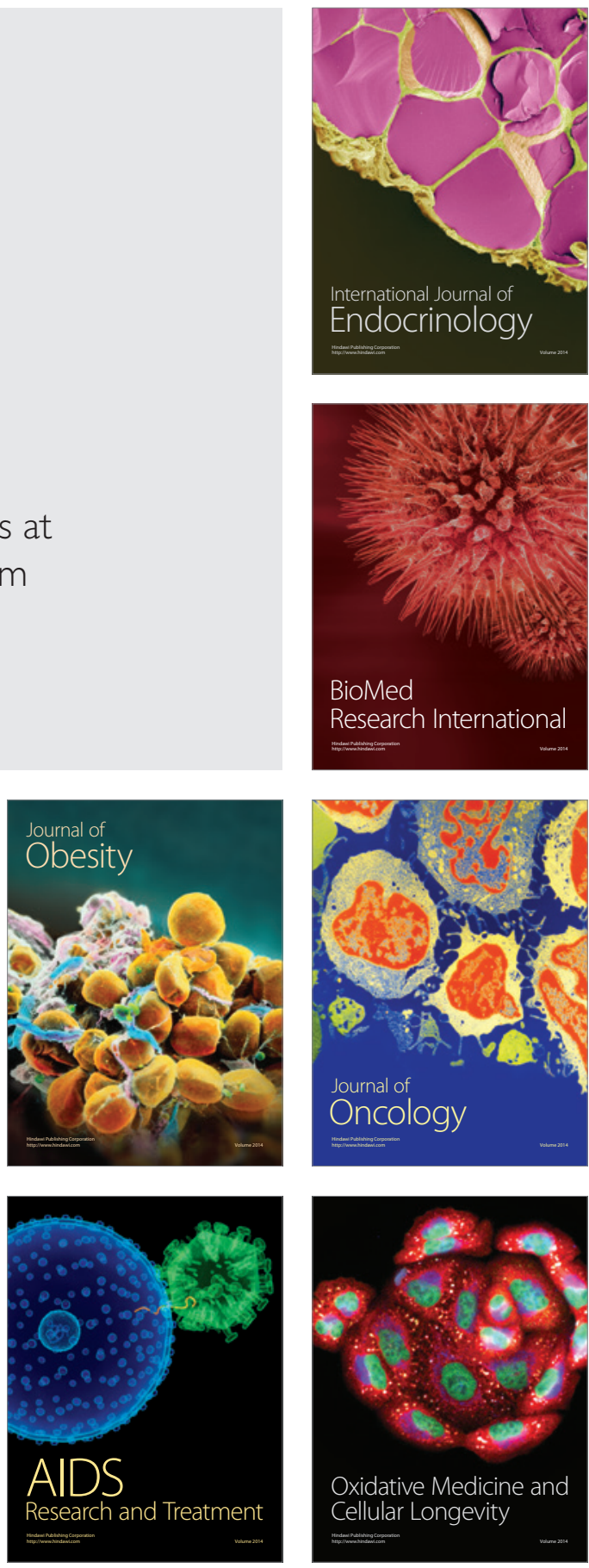